\title{
Bored teenagers
}

\author{
Howy Jacobs
}

$M$ ost of us have experienced that excruciating silence that often descends at the end of a scintillating seminar or even a symposium talk. We have invited a leading world expert to deliver a feisty lecture on the state-of-the-art and the ferment of ideas unleashed by their own findings. They have fulfilled the brief admirably, sticking zealously to the appointed 45-min time-slot, leaving ample time for discussion and avoiding the dip in consciousness that befogs any audience some time after a healthy a dose of cupcakes and strong coffee, or whatever other enticement was provided to ensure they all showed up.

On the other side of the podium, the speaker feels a reciprocal sense of distress: have I bored them all to death? Did they follow a single word or have I failed to explain properly what the work was all about? Did I adequately ascertain their background when I accepted the invitation? Why didn't someone tell me the microphone wasn't working? Did I make an embarrassing gaffe, which ruined the whole talk? Is my life's work of any significance at all?

The silence is usually broken only when a senior professor finally raises a hand. After that, typically another senior professor: before one or two students or postdocs finally venture above the parapet.

The causes of this reticence are not obvious, but it must reflect a combination of the way we train young scientists and "cultural" factors, evident from the fact that the problem differs markedly between countries. The idea that the professor is always right, even when he or she is obviously wrong, is deeply ingrained in much of the world. The USA was, in bygone days, a shining example of the opposite phenomenon. But the fact that more and more $\mathrm{PhD}$ students come from abroad seems to have dampened this tradition. Or maybe those of us who complain about student reluctance to engage in discussion may just be suffering from "old-farts' syndrome," forgetting that it has always been like this.

The most common reasons people give, in private, for not asking questions in seminars are fear of exposing their own ignorance or lack of understanding complex points put forward by the speaker. The presence of seniors from their own department often seems to be an intimidating factor. On the other hand, young scientists are not-or should not be-like teenagers embarrassed to say what they think in front of their parents and their parents' friends. If a key point elaborated by the speaker was unclear, it's most likely that the point wasn't adequately explained. Asking for clarification often allows the speaker to explain the point more cogently, or discuss the complex or unresolved issues lurking in the background that were felt too difficult, or too specialized to have been presented in the main talk. Most often, the student's own ignorance is shared with the rest of humanity, including the speaker. Asking the apparently dumb question shines a light on the unanswered or unaddressed aspects of the topic.

In the long term, I believe that we can only deal with this problem by sharpening the "critical thinking" of high-school (and undergraduate) students. We need to give more credit to those who reason aloud and express their opinion. We need them to grasp that ideas advance only by most of us being wrong most of the time, and they are part of that process even in a high-school class. Accordingly, we need to change the criteria by which we select students for university science courses. Currently, too many entrance exams test only the ability to remember book knowledge.

In the shorter term, and at local level, we can build meaningful incentives - and even corresponding penalties - into our graduate education programmes. It is often a struggle not only to get graduate students to ask questions of seminar speakers, but even to persuade them to meet with them one-onone to discuss their own work. So one answer may be to make such meetings (and their documentation) compulsory.

Another approach that seems to work is to follow up the "official" seminar with the $\mathrm{PhD}$ students meeting in small groups, to discuss the material and formulate questions for the speaker that are then delivered and discussed in a structured Q\&A session without the senior faculty being present, before the speaker finally leaves. Even if at first this feels like an additional ordeal, once it becomes commonplace, it is also liberating and enlightening.

Although these tasks seem like a timeout from the daily tasks of data acquisition, $\mathrm{PhD}$ students and postdocs surely understand that a successful career in science, and indeed, the future of science itself, depends on critical discourse, not just on being a dutiful technician. In any case, the serious scientist's workday does not end at 5 p.m. There is ample time to go back to the laboratory afterwards. Or even better, for a beer with the speaker.

\section{Conflict of interest}

The author declares that he has no conflict of interest. 